\title{
Archaeology that counts: International colloquium on digital archaeology
}

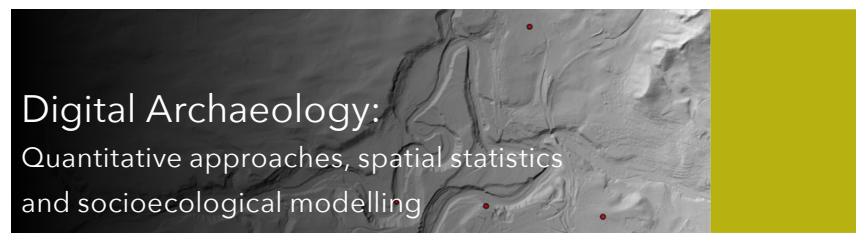

\author{
Martin Hinz ${ }^{1,2}$, J. Laabs ${ }^{1,2}$ and M.E. Castiello \\ Bern, Switzerland, 4-6 February 2019
}

Quantitative methods are transforming how archaeology approaches the investigation of the human past. The emerging possibilities of data integration and computational modeling enable interdisciplinary research on a new level. In large part due to the current challenges imposed by climate change, there is a growing awareness of the importance of past environmental conditions on human history. Archaeology possesses an unmatched record of societal responses to such changes, which can only be utilized by integrated research and quantitative analysis.

In order to facilitate the exchange of knowledge from recent research in this field, the Institute of Archaeological Sciences and the Oeschger Centre for Climate Change Research at the University of Bern, Switzerland, organized the first International Colloquium on Digital Archaeology in Bern. For two days, 60 participants from different disciplines, many of whom were young academics, exchanged information on the status and potential of digital archaeology and socioecological modeling as an integral part of responsible and relevant research approaches. The diverse and valuable contributions were complemented by the keynote speakers' inspiring talks.

Oliver Nakoinz (University of Kiel, Germany) started by situating digital and quantitative archaeology both thematically and historically. He pointed out that only integrative research that realistically reflects both societal and environmental influences on human development enables us to make meaningful statements about the past. The main part of the lecture therefore established quantitative archaeology not only as an integral part of archaeology itself, but rather as a natural link between the scientific approach aimed at structural analysis and the traditional approach of the humanities aimed at negotiating historical meaning and developing narratives.

Many of the following contributions dealt with quantitative approaches in spatial and non-spatial archaeological case studies as well as data-mining and new techniques of supervised and unsupervised pattern recognition in archaeological and ecological data. Juan Barceló's (Universitat Autònoma de Barcelona, Spain) keynote closed the first day and opened a rich final discussion with his pointed and provocative lecture. He reflected on the challenges and opportunities of big data and machine learning for a subject like archaeology and made his position clear that scientific archaeology can only be quantitative. This did not go unchallenged, and an active debate arose, which only ended because of the conference program's time restraints.

The following day was opened by Mikhail Kanevski (University of Lausanne, Switzerland), who, from the perspective of computer science, showed the unexplored potential of artificial intelligence. He spoke about machine learning in the field of geospatial data and demonstrated that this tool is one of the most promising for the investigation of complex environmental phenomena. Especially when considering the multilayered human influence, it is of utmost importance to separate effective factors from noise for specific research questions. His contribution was an enormous enrichment for the methodological scope of the colloquium.

The conference ended with a lecture from Michael Barton (Arizona State University, USA). He stated that the time of purely reconstructive archaeology is over, because reconstructing the past has turned out to be impossible. Rather, it is necessary to use the long-term perspective and the far-reaching data of archaeology for questions regarding the interaction between humans and the environment and to enable robust testing of assumptions about human dependency and decision making with regard to environmental change through explicit, quantitative and computer-supported models. This can position the discipline as an important driver in current discussions.

The colloquium and the discussions showed that archaeology is on the brink of fundamental changes in handling and analyzing big data and complex systems. This will not only impact the discipline itself but will influence the interdisciplinary work in which archaeology is involved. Digital and quantitative archaeology is an important interface between the natural sciences and the humanities for the investigation of long-term human-environment interactions in the past and their added value for today's discourses. This perspective is already advocated by the PAGES LandCover6k and PEOPLE 3000 working groups.

We, therefore, were happy that PAGES endorsed the colloquium and offered us the opportunity to demonstrate why conferences and workshops connected to digitization and quantitative approaches in the field of archaeology are important for the future collaboration between (paleo-)environmental/ climate and (pre-)historic sciences.

The colloquium's abstract booklet can be accessed at: doi.org/10.5281/zenodo.2628304

\section{AFFILIATIONS}

${ }^{1}$ Institute of Archaeological Sciences, University of Bern, Switzerland

${ }^{2}$ Oeschger Center for Climate Change Research, University of Bern, Switzerland

\section{CONTACT}

Martin Hinz: martin.hinz@iaw.unibe.ch 